This paper is a postprint of a paper submitted to and accepted for publication in IET Renewable Power Generation (RPG) and is subject to IET copyright. The copy of record is available at [http://digitallibrary.theiet.org/]" and the paper is available through IEEE Xplore at [http://ieeexplore.ieee.org/xpls/abs_all.jsp?arnumber=5497937]

\title{
Supporting high penetrations of renewable generation via implementation of real-time electricity pricing and demand response
}

\section{A.J. Roscoe and G. Ault}

\begin{abstract}
:
The rollout of smart meters raises the prospect that domestic customer electrical demand can be responsive to changes in supply capacity. Such responsive demand will become increasingly relevant in electrical power systems, as the proportion of weather-dependent renewable generation increases, due to the difficulty and expense of storing electrical energy. One method of providing response is to allow direct control of customer devices by network operators, as in the UK "Economy 7" and "White Meter" schemes used to control domestic electrical heating. However, such direct control is much less acceptable for loads such as washing machines, lighting and televisions. This paper instead examines the use of real-time pricing of electricity in the domestic sector. This allows customers to be flexible but, importantly, to retain overall control. This paper presents a simulation methodology for highlighting the potential effects of, and possible problems with, a national implementation of real-time pricing in the UK domestic electricity market. This is done by disaggregating domestic load profiles and then simulating price-based elastic and load-shifting responses. Analysis of a future UK scenario with $15 \mathrm{GW}$ wind penetration shows that during low-wind events, UK peak demand could be reduced by $8-11 \mathrm{GW}$. This could remove the requirement for $8-11 \mathrm{GW}$ of standby generation with a capital cost of £2.6 to $£$ 3.6 billion. Recommended further work is the investigation of improved demand-forecasting and the price-setting strategies. This is a fine balance between giving customers access to plentiful, cheap energy when it is available, but increasing prices just enough to reduce demand to meet the supply capacity when this capacity is limited.
\end{abstract}


This paper is a postprint of a paper submitted to and accepted for publication in IET Renewable Power Generation (RPG) and is subject to IET copyright. The copy of record is available at [http://digitallibrary.theiet.org/]" and the paper is available through IEEE Xplore at [http://ieeexplore.ieee.org/xpls/abs_all.jsp?arnumber=5497937]

\section{Introduction}

In 2008, the UK government set a target for a $\mathrm{CO}_{2}$ emission reduction of $80 \%$ by 2050 , relative to the 1990 baseline [1]. One of the major requirements will be a large increase in the quantity and proportion of electricity generated from variable renewable sources, such as wind, wave, tidal and solar power. Although the variability of renewable resources can be mitigated by aggregating generation over large areas [2],[3],[4], the potential for mid-winter low-wind, low-temperature, events still exists. For example, [2] reports that $50 \%$ of UK wind turbines might experience low-wind (zero output) events coincidentally, for 100 hours per year on average. During such times, if demand was inflexible, the electrical power system would need to be balanced using only a combination of operating reserve (standby generation), imports via international interconnectors, and storage capacity [4],[5],[6],[7],[8]. The capacity factor of standby generation is low [4], making it unattractive from financial and efficiency standpoints, while electrical storage schemes are difficult, expensive or inefficient to realise at the required scales [9],[10]. Currently, UK pumped storage schemes allow $27 \mathrm{GWh}$ to be stored, while requirements in 2050 may be of the order of $1200 \mathrm{GWh}$ [11].

These balancing requirements can be reduced by allowing flexibility in demand. This could be achieved via centralised control of domestic appliances. However, [12] reports that customers would want the ability to reject the control action for a fiscal penalty, but would expect a fiscal reward for compliance. Such a scheme can be much more simply implemented by issuing price-based signals and allowing customers to respond as they see fit [13]. For a few large industrial and commercial consumers, such real-time pricing options are already available [14]. However, for domestic customers such schemes have only existed as limited implementations or small-to-medium scale trials, for example [15],[16],[17],[18],[19],[20]. These trials have often involved time-of-use tariffs which are not truly real-time, but which offer preset daily price fluctuations or definition of a number of preset daily price profiles which can be enforced with reasonable notice. For example, [15] used "blue", "white" and "red" days, and the tariff decision was 
This paper is a postprint of a paper submitted to and accepted for publication in IET Renewable Power Generation (RPG) and is subject to IET copyright. The copy of record is available at [http://digitallibrary.theiet.org/]" and the paper is available through IEEE Xplore at [http://ieeexplore.ieee.org/xpls/abs_all.jsp?arnumber=5497937]

communicated to customers by $8 \mathrm{pm}$ the previous evening. To date, the problems with rolling out such schemes on a nationwide scale include:

- $\quad$ transmitting the prices to the customers

- $\quad$ enabling customers to respond effectively

- $\quad$ metering and billing

However, the UK government now has a target of installing smart meters in every home by 2020 [21], which largely solves these problems. Similar large-scale rollouts of smart-meters are occurring in other countries [22].

It has been recognised that, in addition to the meter itself, a visible real-time information/control panel is required, both to encourage general energy reduction [23], and to allow price-based responses. Some of these responses will require the customer to see the panel and consciously react in real time, but some responses such as load-shifting may be automated by the panel/controller or smart appliances, as allowed by the customer and how he/she wants to react to varying prices.

Although the costs of implementing price-based demand response compare favourably with the costs of alternative balancing measures [24], and the results of several trials are known [15-20], large questions still remain regarding real-time or flexible-tariff pricing, especially if such schemes were made available to a nationwide domestic market. There are communication and data management challenges which should be largely overcome during the imminent smart-meter rollouts, and also significant socio-economic challenges concerning tariff options and their acceptability to consumers including those within fuel poverty [12]. This paper does not seek to solve these problems, but focuses instead on:

1) assessing the likely financial benefits of such tariffs, both for consumers and the power network in general, through reduced peak demands and availability of cheaper energy during off-peak periods ...

2) and predicting the possible problems with implementing real-time pricing, by examining the difficulty in predicting demand and setting prices in an environment 
This paper is a postprint of a paper submitted to and accepted for publication in IET Renewable Power Generation (RPG) and is subject to IET copyright. The copy of record is available at [http://digitallibrary.theiet.org/]" and the paper is available through IEEE Xplore at [http://ieeexplore.ieee.org/xpls/abs_all.jsp?arnumber=5497937]

where price and demand are co-dependent.

More specifically, the following questions are posed:

- What levels of national demand reduction would be achievable, and over what timeframes?

- How could demand be forecast, if it is responsive to price?

- What variation in prices would be required, and how could prices be set?

- Would customers perceive the tariffs as better value (or more preferable) than the fixed-price alternative?

The analysis presented in this paper aims to provide an insight to these questions, by taking known national data and extrapolating from existing small-scale trial data. In this way, potential problems with a national rollout can be highlighted before they are met in reality. A time-domain simulation architecture is presented which allows likely domestic customer response to be modelled at a national scale, when exposed to real-time prices of electricity. The results of such a forward-looking simulation will always only be a guide, due to the limited nature of the known data and the variability in future scenarios. Thus, the approach is to implement a simulation to an appropriate resolution, to highlight approximate likely responses, and to highlight major issues which may arise due to price-setting strategies or customer response modes.

\section{$1.1 \quad$ Simulation process}

To simulate the effects of real-time pricing, the following process is followed, which is described in sections 2-5:

- A set of generic disaggregated domestic load profiles are generated, with different weekly profiles for different load types (e.g lighting, washing machines, fridges etc.), averaged across all households. In this paper we have concentrated on presenting an analysis based upon present profiles of UK electricity consumption, although input data could be modified to represent other future scenarios. 
This paper is a postprint of a paper submitted to and accepted for publication in IET Renewable Power Generation (RPG) and is subject to IET copyright. The copy of record is available at [http://digitallibrary.theiet.org/]" and the paper is available through IEEE Xplore at [http://ieeexplore.ieee.org/xpls/abs_all.jsp?arnumber=5497937]

- A "baseline" simulation is run, using these profiles in a fixed price environment.

- A "demand response" simulation is run, during which price is varied due to forecasts of demand and generation, and customer loads vary via elastic (section 4) and load-shifting (section 5) mechanisms.

An important part of the model is that load-shifting is simulated discretely over many households. This is important, since such load-shifting may be controlled automatically by panels or smart appliances as described above. Thus, there is the potential for either diverse or correlation action, depending upon the difference or similarity with which the automated actions are configured. The model includes algorithms for predicting demand, generation, and in particular, the setting of price. These algorithms are relatively simple at present, but could be substituted for more intelligent algorithms as they are developed.

In this paper we have concentrated on presenting an analysis which uses present rates of UK electricity consumption as a baseline. Case studies 1 and 2 examine how the UK demand profiles might be modified from this baseline, with a high penetration of wind power, if prices varied in real-time.

\section{Disaggregation of baseline load profiles}

Examples of typical UK aggregate load profiles can be obtained from [25]. However, this gives no indication of the contributions from different sectors. Disaggregated UK annual energy consumption data can be obtained from [26],[27] which provides data split into sectors such as industrial, commercial and domestic. The domestic data is also further split into different load types (Table 1). However, this disaggregated data contains no time-domain information. To gather such information is a difficult task [28], and does not lend itself to modelling future scenarios. Therefore, to create a flexible simulation of appropriate resolution, the shapes of the disaggregated load profiles, in a baseline environment of fixed-prices, are estimated over a 7-day period, accounting for likely human/load behaviour due to the time of day and the differences at weekends. The 
This paper is a postprint of a paper submitted to and accepted for publication in IET Renewable Power Generation (RPG) and is subject to IET copyright. The copy of record is available at [http://digitallibrary.theiet.org/]" and the paper is available through IEEE Xplore at [http://ieeexplore.ieee.org/xpls/abs_all.jsp?arnumber=5497937]

profile shapes are transformed into magnitudes, by matching the energy use for each appliance type per over a whole year with the published figures in [26],[27]. For lighting and space-heating load types, the demand profile magnitudes are additionally correlated in time to an input weather data set [29], which links the lighting and heating use to temperature and light levels. The resulting disaggregated profiles are baseline profiles, at fixed prices. In this paper, the baseline price is set at $12.5 \mathrm{p} / \mathrm{kWh}(£ 125 / \mathrm{MWh})$, representing present/imminent energy prices, concurrent with the data of Table 1.

Examples of 3 of the disaggregated load profiles, and the total domestic load profile, are shown in Fig. 1, for a typical late-winter weekday. When the total domestic load profile is added to the commercial and industrial load profiles from the same day, a typical result is shown on Fig. 2. There is reasonable agreement between both the magnitude and shape of the synthesised profile compared to actual UK demand data [25]. This indicates that the described method for disaggregating and then recombining the load profiles is accurate, to an appropriate resolution.

\section{Simulating demand elasticity}

Given a demand elasticity $E$ for a given product, the level of demand $D$ can be calculated for a given price $P$, based upon a reference demand and price $\left(D_{0}, P_{0}\right)$, by the formula for arc elasticity (1) [30]. Note that $E$ is usually negative.

$$
E=\frac{\% \text { change in demand }}{\% \text { change in price }}=\frac{\left(\frac{2 \cdot\left(D-D_{0}\right)}{\left(D+D_{0}\right)}\right)}{\left(\frac{2 \cdot\left(P-P_{0}\right)}{\left(P+P_{0}\right)}\right)}
$$

The level of demand $D$ can thus be calculated by (2), which is derived directly from (1).

$$
D=D_{0} \frac{(1+a)}{(1-a)} \text { where } a=E \frac{\left(P-P_{0}\right)}{\left(P+P_{0}\right)}
$$

Load types which are purely elastic (i.e. which have no potential for load-shifting), can be 
This paper is a postprint of a paper submitted to and accepted for publication in IET Renewable Power Generation (RPG) and is subject to IET copyright. The copy of record is available at [http://digitallibrary.theiet.org/]" and the paper is available through IEEE Xplore at [http://ieeexplore.ieee.org/xpls/abs_all.jsp?arnumber=5497937]

simulated by simply taking the baseline (fixed price) load profiles from section 2 , and modifying the magnitudes/shapes by (2), using the real-time price signal, which will be determined in section 5. In general, elastic response of demand is caused by conscious (and not automated) customer responses to price.

\section{$4 \quad$ Simulating domestic load shifting}

Customers can also respond to fluctuating prices by load shifting certain types of domestic load. Lighting, cooking and brown appliances are less suitable load types to be shifted, but wet loads could easily be shifted, by allowing appliances to execute their run cycles at any sensible times of low prices, before the clean items are required. Cold appliances can also be used to load-shift with the constraint that temperatures be maintained within allowable bounds.

Simulating load-shifting with appropriate resolution is much more complex than simulating elastic behaviour. The approach taken here is to simulate a large number of discrete households individually, using quantised, shiftable load events. Events are described by the typical power and duration. For example, cold events have a typical power of $150 \mathrm{~W}$ and a duration of 0.5 hours. This simulates a fridge running on a duty cycle; switching on in half-hour bursts and switching off for a period. For wet events, the nominal power is typically $2 \mathrm{~kW}$, with a duration of 1 hour, simulating a $2 \mathrm{kWh}$ wash or dry cycle. Thus, for individual simulated houses, the wet and water load-types lead to demand spikes, while the cold load type will be more consistent on a fairly steady duty cycle [28]. Only when many houses are simulated and the demands aggregated is a smooth load curve obtained.

Within each household, the probability of events starting during each half-hour period in the baseline simulation is proportional to the shape of the baseline disaggregated demand profile for each particular load type; i.e. more washing machine cycles will start when the wet demand is at its peak than at its minimum. Also, the probability of events starting during each half-hour period is inversely proportional to the energy use per event; i.e. fewer washing machine cycles are required to create the demand profile if each machine 
This paper is a postprint of a paper submitted to and accepted for publication in IET Renewable Power Generation (RPG) and is subject to IET copyright. The copy of record is available at [http://digitallibrary.theiet.org/]" and the paper is available through IEEE Xplore at [http://ieeexplore.ieee.org/xpls/abs_all.jsp?arnumber=5497937]

cycle uses more energy. Given the probability of event starts against time, the simulated event starts can be placed by using Poisson distributions for each household, for each shiftable load type, at every time period. The cumulative probability of having $m$ or less event starts in each period is given by:

$P(m)=\sum_{k=0}^{m} P(k)$ where $P(k)=\frac{(n p)^{k} e^{-n p}}{k !}$

where $P(k)$ is the probability of $k$ event starts occurring during each time period, and $n p$ is the average number of event starts expected during each time interval. The number of the simulated event starts $m$ can be placed for each house, for each shiftable load type, in each period, by choosing a uniform random number $r$ between 0 and 1 , and then evaluating $P(m)$ successively with $m$ starting at 0 and rising incrementally until $P(m)$ is larger than $r$.

In the demand-response simulation, for load types which can be shifted, the elasticity model (2) is first applied to each different load type at each time period. In this case, the number of event starts for each load type at each time for each household is adjusted up or down by quantised integer amounts using a modification to the process described by equation (3). Next, the event starts can be shifted using simulations of the automatic smart meter/controllers/appliances. This allows loads to be shifted without the user needing to be present or awake. Every customer's smart meter/controller receives the same rolling 24-hour (48 period) advance price forecast (see section 5 ). The controllers form an opinion of average price $P_{a v g}$ by taking the rolling stream of billed prices, and passing this through a low-pass (exponentially decaying) filter with an exponential "half-life" of 7 days. This is implemented as a simple digital filter, having 48 timesteps per day, with the transfer function:

$\frac{(1-\alpha)}{\left(1-\alpha \cdot z^{-1}\right)}$ where $\alpha=e^{\left(\frac{-\ln (2)}{7 \times 48}\right)}$.

Thus, the (unitless) relative price index $R=P / P_{\text {avg }}$ at each time period gives a relative 
This paper is a postprint of a paper submitted to and accepted for publication in IET Renewable Power Generation (RPG) and is subject to IET copyright. The copy of record is available at [http://digitallibrary.theiet.org/]" and the paper is available through IEEE Xplore at [http://ieeexplore.ieee.org/xpls/abs_all.jsp?arnumber=5497937]

measure of the expense of buying electricity. Each household can set their own personalised value of $R_{\text {shift }}$, a unitless relative threshold against which $R$ is checked. When $R$ rises above $R_{\text {shift }}$, the controller, having access to the 24-hour (provisional) price forecast, will attempt to re-schedule the load for the period with the lowest forecast price within an allowable future timeframe. The controller also allows for "critical peak" load shifting which can occur only when $R$ rises above a higher threshold $R_{\text {critical }}$. This can be used to trigger loads such as fridges to be shifted during very high price periods, without shifting them during normal day-to-day price fluctuations.

\section{$5 \quad$ Forecasting and price-setting}

In the UK, a rolling demand forecast is provided by the system operator, with a 48 hour (96 trading period) look-ahead. The existing algorithms for this forecast are not available in the public domain. Additionally, such existing algorithms do not need to (and are not designed to) take account of the effects of real-time prices to which significant proportions of the population can react. These prices are themselves dependent upon demand, and so price and demand become co-dependent Therefore, for the purposes of this paper, a new but simple demand forecasting model has been created. This "learns" from previous demand trends over 15 days, and provides a demand forecast up to 24 hours (48 periods) in advance. The algorithm (Fig. 3) first uses a linear regression to find the mean and slope of the past demand data. This mean and slope is subtracted from the data to leave a residual dataset. Next, a Fourier analysis of the residual dataset is used to find the 5 largest harmonic components of the underlying demand. Such a process is similar to that used for forecasting tide heights, developed by Thomson and Doodson in the 1860's to 1920's [31]. Typically, this finds components with periods of 7 days (weekly variations), 1 day (daily cycle fundamental), and integer fractions of days (defining the shape of the daily profile). The mean, slope, and harmonic components can be projected into the future to provide a simplistic but believable demand forecast, of sufficient accuracy for basic modelling. To account for short-term weather effects and demand elasticity, the forecast must also be adjusted. This is achieved as shown in Fig. 3, using the measured errors in the forecasts from the previous $N$ periods, times a gain factor $k$. Setting $N=1$ can 
This paper is a postprint of a paper submitted to and accepted for publication in IET Renewable Power Generation (RPG) and is subject to IET copyright. The copy of record is available at [http://digitallibrary.theiet.org/]" and the paper is available through IEEE Xplore at [http://ieeexplore.ieee.org/xpls/abs_all.jsp?arnumber=5497937]

lead to large oscillating fluctuations in demand forecast, price and actual demand, via the feedback loop formed by an elastic demand. In this paper, $N$ has been set to 2 , and $k$ to 0.5. Within this paper, for simplicity, the forecast of available generation (supply) capacity is produced using the same algorithm. In reality, knowledge of generation availability and weather forecasting would be used to create a more accurate forecast.

The real-time price to be passed to consumers is determined from the forecasts of supply and demand. As demand approaches the supply capacity, the price must rise: both to represent the marginal cost of the peak-lopping generating units which may need to be brought on-line, and also to signal a change in elastic demand.

Pricing of electricity at the wholesale level is a complex process. In future, the real-time price sent as forecasts and applied to domestic customers may be derived from wholesale market prices, or it may need to be derived in a different fashion. In this paper, the real-time price sent to customers is determined by curves fitted to typical data from the UK balancing mechanism [25]. The system buy price (SBP) was tabulated against the actual system demand over 12 representative days during late spring 2008, which included times when demand approached the supply capacity (Fig. 4). The maximum recorded demand for England and Wales was $\sim 44 \mathrm{GW}$, with available capacity in the region of 50GW (deduced from a $\sim 6 G W$ "surplus" generation forecast from [25]). However not all of the $\sim 6 G W$ surplus capacity would be available instantly and the effective spinning capacity over the timeframe of interest would be closer to $45 \mathrm{GW}$. The pricing model is a curve fitted to this data. The first step is to calculate a normalised value $x$, which rises to unity as demand approaches the supply capacity.

$x=\frac{\text { Demand }}{\text { SupplyCapacity }- \text { BiggestGen eratorCapacity }}$

The factor $x$ accounts for the capacity of the largest generator. When demand is close enough to the supply capacity that power must be purchased from the largest single 
This paper is a postprint of a paper submitted to and accepted for publication in IET Renewable Power Generation (RPG) and is subject to IET copyright. The copy of record is available at [http://digitallibrary.theiet.org/]" and the paper is available through IEEE Xplore at [http://ieeexplore.ieee.org/xpls/abs_all.jsp?arnumber=5497937]

generator in order to avoid a shortfall, it becomes pivotal in the marketplace and price rises rapidly. The price curves can then be created using (5), where $A, B$ and $C$ are fitted coefficients, and $P$ is the price in $\mathrm{f} / \mathrm{MWh}$.

$P=A e^{B x}+C$

Four candidate curves are shown on Fig. 4. The price curves are capped at $1000 \mathrm{f} / \mathrm{MWh}$. The "Least squares fit" curve is technically the exponential curve fit with the lowest variance of error $\left(2574 \mathrm{E}^{2}\right)$. However, this curve presents an almost flat price until a very sharp knee occurs at $\approx 42 \mathrm{GW}$ and then price rises extremely sharply. As will be shown later, such a high demand/price gradient is undesirable, since it creates a high gain and potential instability in the closed-loop "control" system of price and demand. The "Least squares fit" curve also does not pass on the cheapest prices to customers when they are available. The "low" curve offers low prices and has a low variance of error $\left(3077 \mathrm{f}^{2}\right)$. It offers a better fit at lower demands, but does not increase prices enough in the critical region of $\approx 40 G W$ (with capacity at $\approx 45 G W$ ) to stimulate demand changes. The "mid" level curve has a slightly higher error variance $\left(3428 \mathrm{E}^{2}\right)$ but crucially offers a good compromise between low prices at low demands, and a steadily increasing price/demand slope as demand approaches supply capacity. The "high" level curve offers undesirably higher prices (fit error variance $8472 \mathrm{f}^{2}$ ) but does have an even steadier price increase when demand approaches supply capacity. The benefit of this will be described later in section 7.

The real-time price charged to customers at the domestic level will be higher than that of the wholesale market system buy price. The overheads consist of a Distribution Use of System (DUoS) charge (nominally $8 \mathrm{f} / \mathrm{MWh}$ in the UK in 2000 [32]), a Transmission Use of System (TuOS) and service charges. In this paper a lumped figure of $\mathrm{f20} / \mathrm{MWh}(2 \mathrm{p} / \mathrm{kWh})$ is added to customer real-time prices, accounting for these components. Even after this addition, the real-time price is usually cheaper than the $12.5 \mathrm{p} / \mathrm{kWh}$ fixed price, but is occasionally much more expensive. 
This paper is a postprint of a paper submitted to and accepted for publication in IET Renewable Power Generation (RPG) and is subject to IET copyright. The copy of record is available at [http://digitallibrary.theiet.org/]" and the paper is available through IEEE Xplore at [http://ieeexplore.ieee.org/xpls/abs_all.jsp?arnumber=5497937]

\section{Case study 1; 15GW wind penetration, conservative elasticities in the domestic sector only}

Case study 1 is simulated using 1000 discrete households (scaled to represent demand from 25 million UK houses) for a 6-week timeframe in the midwinter season. Generation capacity is set at $48 \mathrm{GW}$ thermal plus $15 \mathrm{GW}$ (peak) wind generation. This level of wind generation is large compared to 2009 levels (3.7GW [33]) but small compared to the 43GW predicted in 2030 by [4]. In the simulation, the wind generation capacity at any time is determined by splitting the $15 \mathrm{GW}$ peak wind capacity into 1500 separate $10 \mathrm{MW}$ wind-farms. Each wind-farm uses the same single-location weather dataset [29] used to determine the heating/lighting load profile magnitudes, however a random time offset between -24 and +24 hours is applied at each wind-farm. This creates a smearing effect to represent the geographical spread of wind-farms across the UK. Although total peak generation capacity is $63 \mathrm{GW}$, enough for UK winter peak demand, during low-wind events the thermal generation capacity of $48 \mathrm{GW}$ is not adequate. Note that we have ignored transmission and distribution losses in this analysis, and that the generation capacities should be regarded as capacities available at the point of end user demand. The baseline simulation for this scenario (Fig. 5), which uses electrical demands at present levels, clearly shows times when daily peak demand surpasses capacity.

In the demand-response simulation, the following changes are applied:

- Conservative elasticities for domestic consumption as per Table 2. These elasticities represent conservative figures compared to claims made by many previous studies of elasticity estimates [16],[17],[19],[20],[34]. Commercial and industrial consumption is set to be inelastic which is artificial but allows case study 1 to show only the potential effects of the domestic sector response.

- $75 \%$ of consumers willing to load-shift wet appliance cycles, with the help of automated controllers/devices, by up to 12 hours, when $R$ exceeds $R_{\text {shift }}=1.25 .100 \%$ of consumers are prepared to load-shift their wet appliances (by 12 hours) and cold appliances (by 3 hours) when R exceeds $R_{\text {critical }}=3$. 
This paper is a postprint of a paper submitted to and accepted for publication in IET Renewable Power Generation (RPG) and is subject to IET copyright. The copy of record is available at [http://digitallibrary.theiet.org/]" and the paper is available through IEEE Xplore at [http://ieeexplore.ieee.org/xpls/abs_all.jsp?arnumber=5497937]

- Pricing is set by the "mid" curve of Fig. 4 and the mechanism described in section 5.

The effect of the demand response on overall demand is shown by the thick line on Fig. 5, which is driven by the prices passed to customers, shown in Fig. 6. The demand is reduced at times of highest prices. The only slight generation shortfall occurs in the late evening on day 23. The response of the most elastic load types during the 2 days of highest prices (Fig. 7) is shown on Fig. 8. The brown demand drops by up to $1.5 \mathrm{GW}$, i.e. approx 15 million appliances at 100W each, or 0.6 appliances per household. The lighting demand also drops by up to $1.5 \mathrm{GW}$, i.e. 60 million lights at $25 \mathrm{~W}$ each, i.e. an average of $2 \frac{1}{2} 225 \mathrm{~W}$ lights per household.

The authors believe that such short-term lighting elasticity can arise because some (but not necessarily all) home-owners will react to high electricity prices and take extra care to turn off unnecessary lights during these times. Conversely, these same people, and others who normally take care to turn off unnecessary lighting, may be less thrifty when electricity is relatively cheap. This particularly applies to ambient (as opposed to functional) lighting, and lighting which, in winter, offsets domestic heating demand, particularly in households using any electrical heating devices. It is also expected that the average daily lighting demand of households may fall from that quoted in Table 1, due to the gradual changeover from tungsten/halogen to energy-saver or LED (light-emitting-diode) bulbs. However, the most recent 2009 data from DECC [35] shows that this transition is, to date, occurring only slowly, with the newer technology bulbs only responsible for $10.6 \%$ of the lighting energy use, and overall domestic lighting demand only reduced by $5 \%$ between 2000 and 2008 .

During the high prices, many wet load events are moved (Fig. 9). Between 09:30 and 21:30 on day 23 , up to $2 \mathrm{GW}$ of wet demand was removed. However, in this simulation, because all domestic controllers were given the same parameter settings and received the same price signal, all the shifted events were re-scheduled to the same forecast cheapest price 
This paper is a postprint of a paper submitted to and accepted for publication in IET Renewable Power Generation (RPG) and is subject to IET copyright. The copy of record is available at [http://digitallibrary.theiet.org/]" and the paper is available through IEEE Xplore at [http://ieeexplore.ieee.org/xpls/abs_all.jsp?arnumber=5497937]

period, between 02:30 and 05:00 on day 24. This creates an undesirable, correlated, $8 \mathrm{GW}$ demand spike. The cold demand is normally a fairly static $2 \mathrm{GW}$ load. Due to the critical peak pricing signals (when $R>3$, see Fig. 7 ), the cold demand can be reduced by $2 \mathrm{GW}$ during many of these times (Fig. 10). The by-product is that the demand must be made up later, which can again result in correlated demand spikes, in this case up to 8GW caused by 3 previous periods of load shifting. This is again due to similarly configured controllers responding to the same price signal.

The total demand reduction at peak times is approximately $8 \mathrm{GW}$, made up predominantly of $\sim 1.5 \mathrm{GW}$ (lights), $\sim 1.5 \mathrm{GW}$ (brown), $\sim 1 \mathrm{GW}$ (space-heating), $\sim 2 \mathrm{GW}$ (wet load shifts), and 2GW (cold load shifts). The accuracy of these values for lights and brown is directly dependent upon the conservative elasticity values assumed in Table 2. If such elasticities are not achievable (or are higher than quoted), then the reductions will be proportionately different. The exact choice of pricing curve will also affect these values. For the peak reductions due to load shifts, the values depend mainly upon the assumed participation rates, and also require that smart appliances are installed. In this scenario, at critical peak prices, the participation rate is $100 \%$. The peak demand reduction values of $2 \mathrm{GW}$ for wet and $2 \mathrm{GW}$ for cold can be shown to be of the right order by taking the average daily consumption values from Table 1 and scaling them to average UK demand in GW. This has been done in the right-hand column of Table 1. The figure for cold is a good match as one would expect. For wet, our simulation shows a higher peak reduction than the average UK wet demand, but this too is expected since at peak times there will be a natural tendency for wet demand to be higher than average.

Case study 1 was also examined over a full annual period, to examine the overall changes in electrical energy demand, and electricity bills, between the baseline (fixed-price) and demand-response (real-time price) scenarios. To do this, the number of discrete houses modelled was reduced from 1000 to 100 , to keep simulation durations and computer memory requirements within acceptable bounds. 
This paper is a postprint of a paper submitted to and accepted for publication in IET Renewable Power Generation (RPG) and is subject to IET copyright. The copy of record is available at [http://digitallibrary.theiet.org/]" and the paper is available through IEEE Xplore at [http://ieeexplore.ieee.org/xpls/abs_all.jsp?arnumber=5497937]

Although the price to customers is fixed in this baseline simulation, the real-time price that would result can still be calculated due to the balance of supply and demand, as described in section 5. During the baseline simulation, over the year, the average market forecast price would have been $11.06 \mathrm{p} / \mathrm{kWh}$ (after the addition of overheads), making the actual customer flat-rate price of $12.5 \mathrm{p} / \mathrm{kWh}$ profitable $(1.44 \mathrm{p} / \mathrm{kWh}$ hedging profit) for the UK electricity providers. This shows that the assumed flat-rate price of $12.5 \mathrm{p} / \mathrm{kWh}$ and the pricing model of section 5 are consistent with one another.

The results of the annual simulation are summarised in Table 3 and Table 4. Notably, in the presence of real-time prices, customers are able to use more electrical energy over the year, but to pay less for it. Table 3 shows that the average daily household electrical demand rose from $12.8 \mathrm{kWh}$ to $13.75 \mathrm{kWh}(+7.4 \%)$, while saving $\mathrm{f} 103(-18 \%)$ at the same time. The magnitude of the average bill reduction arises from two contributing factors. Firstly, the energy providers no longer take a hedging profit of $1.44 \mathrm{p} / \mathrm{kWh}$ on each of the $\sim 4750 \mathrm{kWh}$ that each household uses each year $(£ 0.0144 * 4750=£ 68.40)$. Secondly, because demand reduces when generation is limited, the average market prices are lower than they are in the baseline (fixed price) simulation. The combination of these two effects leads to the average household saving of $\mathrm{f} 103$. Table 3 also shows how the actual energy use and bill reductions vary between different types of household. In the case of households with electric water and space heating, note that in the baseline simulation, the effects of legacy pricing schemes such as Economy 7 and White Meter have not been included, which would reduce the baseline costs. Table 4 provides a further breakdown of the effects of implementing real-time prices, for 4 of the appliance types.

\section{$7 \quad$ Case study 2; larger elasticities, non-domestic response, and lowered thermal generation capacity}

Case study 2 is based upon case study 1 , but uses more optimistic elasticity figures for domestic demand (Table 2) and also includes conservative elasticities of -0.1 for the 
This paper is a postprint of a paper submitted to and accepted for publication in IET Renewable Power Generation (RPG) and is subject to IET copyright. The copy of record is available at [http://digitallibrary.theiet.org/]" and the paper is available through IEEE Xplore at [http://ieeexplore.ieee.org/xpls/abs_all.jsp?arnumber=5497937]

commercial and industrial sectors to illustrate the combined effect of all consumers. This enables thermal generation capacity to be reduced from $48 \mathrm{GW}$ to $45 \mathrm{GW}$. An example of the response is shown in Fig. 11. The total demand reduction at peak times is approximately $11 \mathrm{GW}$. Of note, however are the beginnings of large high-frequency oscillations in the pricing signals (Fig. 12) which subsequently affect demand with a rippling effect. This is caused by the high gain (elasticity) of the customer response to half-hourly price changes, combined with the steep gradient of the "mid" price curve (Fig. 4), and the primitive nature of the forecasting and price-setting algorithms employed during these simulations. The oscillations (for a given level of elasticity) can be reduced by either of the following actions which re-stabilise the "control loop" formed by pricing control and customer response:

- $\quad$ More intelligent forecasting/pricing algorithms

- Reduction of the gradient of the price curve, for example to the "high" price curve shown on Fig. 4. This lowers the gain of the feedback system. There are two significant drawbacks to this solution. The first is that the price given to customers is higher than it needs to be when demand is low. The second is that the price gradient may not be high enough to create enough elastic response when demand approaches the supply capacity.

\section{$8 \quad$ Conclusions and further work}

In the case studies presented, the results show that a demand reduction of between $8 \mathrm{GW}$ and $11 \mathrm{GW}$ at times of peak demand and low-wind could be achieved in the UK, due to elasticity and load-shifting. This is significant, since this would remove the requirement for $8-11 \mathrm{GW}$ of thermal standby generation or storage. The capital cost of such generation

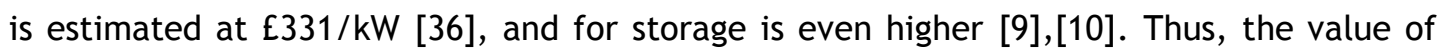
the implementation of real-time pricing would be at least $£ 2.6$ to $£ 3.6$ billion. The actual value will be higher due to the recurring reduction in standby/storage operating costs (approx £418m p.a. for 6.5GW [3], but potentially lower for low-maintenance storage schemes with high round-trip efficiency). Thus, over a 10-year timeframe, the offset cost of standby generation could be $\mathrm{f} 7$ to $\mathrm{£} 11$ billion, or around $\mathrm{£} 300-400$ for each of the 25 
This paper is a postprint of a paper submitted to and accepted for publication in IET Renewable Power Generation (RPG) and is subject to IET copyright. The copy of record is available at [http://digitallibrary.theiet.org/]" and the paper is available through IEEE Xplore at [http://ieeexplore.ieee.org/xpls/abs_all.jsp?arnumber=5497937]

million UK households. This benefit could be used to justify the expense of installing and operating the smart meters. The total value (and viable cost) of smart meters will be even higher than this figure since they bring additional functionality such as automated meter readings and instrumentation capability in a smart grid context.

The case studies suggest that many customers will perceive the real-time pricing tariffs as better value than the fixed-price tariffs, since, on average, simulated customers on real-time pricing tariffs manage to use more energy, but by spending less. This also highlights one reason why electricity suppliers may be reluctant to initially offer such tariffs, since their hedging profits will be reduced.

The case studies also highlight three significant problems which would need to be addressed before a nationwide rollout of real-time pricing could occur. Firstly, as previously described in [37], more intelligent demand-forecasting algorithms are required and questions about the responsibility and cost for providing this remain. These will probably need to be adaptive algorithms, and must learn to account for the changes in demand which occur due to price changes, as well as the time/date and weather conditions. Secondly, price must be set appropriately. This is a fine balance between giving customers access to plentiful, cheap energy when it is available, but increasing prices just enough to reduce demand to meet the supply capacity when this capacity is limited. Increasing the price too far both penalises customer unnecessarily and can cause a larger demand reduction than is required. In the extreme, this can lead to an oscillating demand/price cycle. The algorithms to set price and forecast demand may need to be integrated, since price and demand will be co-dependent.

Thirdly, if automated energy display panels or smart appliances are used within households to implement load-shifting, then the possibility exists for all households to correlate their re-scheduled loads to the same times, causing a new demand spike where one otherwise would not have existed. This is especially true if all households use controllers of 
This paper is a postprint of a paper submitted to and accepted for publication in IET Renewable Power Generation (RPG) and is subject to IET copyright. The copy of record is available at [http://digitallibrary.theiet.org/]" and the paper is available through IEEE Xplore at [http://ieeexplore.ieee.org/xpls/abs_all.jsp?arnumber=5497937]

appliances which contain similar algorithms and use similar default parameters, and receive the same price signals. Ways to mitigate such unwanted behaviour could be:

- Issuing different prices to different customers. A range of tariffs could accomplish this. Prices could also be location-based, as suggested by [37] [38], both to reduce nationally correlated demand spikes, and to assist in power flow constraint management.

- Use of low-end caps on real-time prices, so that no single price period is the cheapest.

- Automated control systems or smart appliances could, by law, be required to contain some degree of randomisation in timing and/or default parameter settings, so that even without customer intervention, some diversity of response will occur.

In the future, electric heating (possibly using ground-source or air-source heat pumps) may become financially competitive with heating from natural gas. Electric vehicles may also become commonplace, with complex charging (and possibly storage-related) profiles [3],[39],[40]. Domestic generation may become significant. The simulation architecture described in this paper could be extended to analyse the potential effects of these high-impact changes to future domestic electricity demand, and interactions with real-time prices.

\section{$9 \quad$ References}

[1] UK Government, 2008 c. 27: 'Climate change act 2008', 2008, http://www.statutelaw.gov.uk/, accessed October 2009

[2] Sinden, G.: 'Characteristics of the UK wind resource: Long-term patterns and relationship to electricity demand', Energy Policy, 2007, 35, (1), pp. 112-117

[3] National_Grid: 'Operating the Electricity Transmission Networks in 2020 - Initial Consultation', National Grid, 2009, http://www.nationalgrid.com/uk/Electricity/Operating+in+2020/, accessed October 2009

[4] Poyry: 'Impact of intermittency: how wind variability could change the shape of the British and Irish electricity markets. Summary report', 2009, 
This paper is a postprint of a paper submitted to and accepted for publication in IET Renewable Power Generation (RPG) and is subject to IET copyright. The copy of record is available at [http://digitallibrary.theiet.org/]" and the paper is available through IEEE Xplore at [http://ieeexplore.ieee.org/xpls/abs_all.jsp?arnumber=5497937]

http://www.ilexenergy.com/pages/documents/reports/renewables/Intermittency \%20Public\%20Report\%202_0.pdf, accessed

[5] Strbac, G., Shakoor, A., Black, M., Pudjianto, D., and Bopp, T.: 'Impact of wind generation on the operation and development of the UK electricity systems', Electric Power Systems Research, 2007, 77, (9), pp. 1214-1227

[6] Black, M., and Strbac, G.: 'Value of storage in providing balancing services for electricity generation systems with high wind penetration', Journal of Power Sources, 2006, 162, (2), pp. 949-953

[7] Black, M., and Strbac, G.: 'Value of bulk energy storage for managing wind power fluctuations', IEEE Transactions on Energy Conversion, 2007, 22, (1), pp. 197-205

[8] Zeineldin, H.H., El Fouly, T.H.M., El Saadany, E.F., and Salama, M.M.A.: 'Impact of wind farm integration on electricity market prices', let Renewable Power Generation, 2009, 3, (1), pp. 84-95

[9] Electricity Storage Association: 'Storage technology comparisons', http://www.electricitystorage.org/site/technologies/, accessed Oct 2009

[10] Brunetto, C., and Tina, G.: 'Optimal hydrogen storage sizing for wind power plants in day ahead electricity market', let Renewable Power Generation, 2007, 1, (4), pp. 220-226

[11] Mackay, D.J.C.: 'Sustainable Energy - without the hot air', 2008, ISBN 978-09544529-3-3), http://www.withouthotair.com/, accessed October 2009

[12] Smart-A: 'Consumer acceptance of smart appliances', Smart-A, D 5.5 of WP 5, 2008, http://www.smart-a.org/WP5_5_Consumer_acceptance_18_12_08.pdf, accessed 29/10/09

[13] Strbac, G.: 'Demand side management: Benefits and challenges', Energy Policy, 2008, 36, (12), pp. 4419-4426

[14] Sheen, J.N., Chen, C.S., and Wang, T.Y.: 'Response of large industrial customers to electricity pricing by voluntary time of use in Taiwan', IEE proceedings in generation, transmission and distribution, 1994, 142, (2), pp. 157-166

[15] Aubin, C., Fougere, D., Husson, E., and Ivaldi, M.: 'Real-time pricing of electricity for residential customers: Econometric analysis of an experiment', Journal of Applied Econometrics, 1995, 10, pp. S171-S191

[16] Filippini, M.: 'Swiss Residential Demand for Electricity by Time-of-Use', Resource and Energy Economics, 1995, 17, (3), pp. 281-290

[17] Baladi, S.M., Herriges, J.A., and Sweeney, T.J.: 'Residential response to voluntary time-of-use electricity rates', Resource and Energy Economics, 1998, 20, pp. 225244

[18] Barbose, G., and Goldman, C.: 'A Survey of Utility Experience with Real Time Pricing', Consortium for Electric Reliability and Technology Solutions (CERTS), LBNL-54238, 2004, http://eetd.lbl.gov/ea/EMS/EMS_pubs.html, accessed $29 / 10 / 09$

[19] DRAM: 'Predicting California Demand Response. Demand response and advanced metering coalition', http://www.dramcoalition.org/id99.htm, accessed June 2008 
This paper is a postprint of a paper submitted to and accepted for publication in IET Renewable Power Generation (RPG) and is subject to IET copyright. The copy of record is available at [http://digitallibrary.theiet.org/]" and the paper is available through IEEE Xplore at [http://ieeexplore.ieee.org/xpls/abs_all.jsp?arnumber=5497937]

[20] NEDRI: 'New England demand response initiative, Dimensions of Demand Response: Capturing Customer Based Resources in New England's Power Systems and Markets', http://nedri.raabassociates.org, accessed August 2009

[21] DECC: 'Energy metering: a consultation on smart metering for electricity and gas', DECC, 2009, http://www.decc.gov.uk/en/content/cms/consultations/smart_metering/smart_ metering.aspx, accessed July 2009

[22] Cotti, M., Salaris, M., and Caleno, F.: 'Design and deploy an innovative indoor device addressing the energy efficiency: a first step toward the smart box leveraging on the existing ENEL AMM infrastructure'. 20th International Conference on Electricity Distribution Prague 2009

[23] OFGEM: 'Ofgem Smart Metering Trial', http: / / www.ofgem.gov.uk/Markets/RetMkts/Metrng/Smart/Pages/SmartMeter.asp $\mathrm{x}$, accessed July 2009

[24] Mathiesen, B.V., and Lund, H.: 'Comparative analyses of seven technologies to facilitate the integration of fluctuating renewable energy sources', IET Renewable Power Generation, 2009, 3, (2), pp. 190-204

[25] ELEXON: 'NETA electricity market view', http://www.bmreports.com/bwx_reporting.htm, accessed July 2009

[26] BERR: 'Energy consumption in the United Kingdom: domestic data tables 2008 update', http: / /webarchive.nationalarchives.gov.uk/+/http://www.berr.gov.uk//files/file 47214.xls, accessed October 2009

[27] BERR: 'UK energy statistics', http://www.berr.gov.uk/energy/statistics/index.html, accessed May 2009

[28] Firth, S., Lomas, K., Wright, A., and Wall, R.: 'Identifying trends in the use of domestic appliances from household electricity consumption measurements', Energy and Buildings, 2008, 40, (5), pp. 926-936

[29] ESRU: 'ESP-r integrated modelling tool. University of Strathclyde', http://www.esru.strath.ac.uk/Programs/ESP-r.htm, accessed July 2009

[30] Allen, R.G.D.: 'The concept of arc elasticity of demand', Review of Economic Studies, 1933, 1, (3), pp. 226-229

[31] Doodson, A.T.: 'The Harmonic Development of the Tide-Generating Potential ', Proceedings of the Royal Society of London. Series A, Containing Papers of a Mathematical and Physical Character, 1921, 100, (704), pp. 305-329

[32] Jenkins, N., Allan, R., Crossley, P., and Kirschen, D.: 'Embedded Generation', (IEE, 2000)

[33] BWEA: 'UK Wind Energy Database - UKWED ', http://www.bwea.com/ukwed/index.asp, accessed August 2009

[34] Filippini, M.: 'Electricity Demand by Time-of-Use - an Application of the Household Aids Model', Energy Economics, 1995, 17, (3), pp. 197-204

[35] DECC: 'Energy consumption in the United Kingdom', http://www.decc.gov.uk/en/content/cms/statistics/publications/ecuk/ecuk.aspx , accessed February 2010 
This paper is a postprint of a paper submitted to and accepted for publication in IET Renewable Power Generation (RPG) and is subject to IET copyright. The copy of record is available at [http://digitallibrary.theiet.org/]" and the paper is available through IEEE Xplore at [http://ieeexplore.ieee.org/xpls/abs_all.jsp?arnumber=5497937]

[36] The Royal Academy of Engineering: 'The Costs of Generating Electricity', http://www.raeng.org.uk/news/publications/list/reports/Cost_of_Generating_Ele ctricity.pdf, accessed August 2009

[37] Kirschen, D.S., Strbac, G., Cumperayot, P., and Mende, D.D.: 'Factoring the elasticity of demand in electricity prices', IEEE Transactions on Power Systems, 2000, 15, (2), pp. 612-617

[38] Jokic, A., van den Bosch, P.P.J., and Lazar, M.: 'Distributed price-based optimal control of power systems', Proceedings of the 2007 IEEE Conference on Control Applications, Vols 1-3, 2007, pp. 918-923

[39] Huang, S., and Infield, D.: 'The Potential of Domestic Electric Vehicles to Contribute to Power System Operation through Vehicle to Grid Technology'. 44th Universities Power Engineering Conference (UPEC), Glasgow, UK, September 2009

[40] Zhong, X., Cruden, A., Infield, D., and Huang, S.: 'Assessment of Vehicle to Grid Power as Power System Support'. 44th Universities Power Engineering Conference (UPEC), Glasgow, UK, September 2009 
This paper is a postprint of a paper submitted to and accepted for publication in IET Renewable Power Generation (RPG) and is subject to IET copyright. The copy of record is available at [http://digitallibrary.theiet.org/]" and the paper is available through IEEE Xplore at [http://ieeexplore.ieee.org/xpls/abs_all.jsp?arnumber=5497937]

\section{Figures \& Tables}

\begin{tabular}{|c|c|c|c|c|c|}
\hline Type & Meaning & $\begin{array}{l}\text { Percentage of } \\
\text { all households } \\
\text { with electrical } \\
\text { load types }\end{array}$ & $\begin{array}{c}\text { Average electrical } \\
\text { demand } \\
\text { kWh/house/day } \\
\text { (all households) }\end{array}$ & $\begin{array}{c}\text { Average electrical } \\
\text { demand } \\
\text { kWh/house/day } \\
\text { (households } \\
\text { without gas) }\end{array}$ & $\begin{array}{c}\text { Approx. } \\
\text { average UK } \\
\text { electrical } \\
\text { demand (GW) } \\
\text { For } 25 \text { million } \\
\text { households }\end{array}$ \\
\hline Lighting & Electric lights & $100.0 \%$ & 2.0 & 2.0 & 2.1 \\
\hline Cooking & $\begin{array}{c}\text { Electric hobs and } \\
\text { ovens }\end{array}$ & $60.0 \%$ & 1.1 & 1.8 & 1.1 \\
\hline Brown & $\begin{array}{c}\text { Consumer electronics } \\
\text { (e.g. TVs) } \\
\text { and home computing }\end{array}$ & $100.0 \%$ & 2.9 & 2.9 & 3.0 \\
\hline Wet & $\begin{array}{c}\text { Washing machines, } \\
\text { tumble dryers, and } \\
\text { dishwashers }\end{array}$ & $100.0 \%$ & 1.4 & 1.4 & 1.5 \\
\hline Water & Electric water heating & $15.0 \%$ & 1.5 & 10.1 & 1.5 \\
\hline $\begin{array}{l}\text { Total } \\
\text { domestic }\end{array}$ & - & - & 13.3 & 37.0 & 13.8 \\
\hline Commercial & - & - & 10.7 & - & 11.1 \\
\hline Industrial & - & - & 12.2 & - & 12.7 \\
\hline
\end{tabular}

Table 1 Average demand of load types, scaled to per-household, per-day amounts

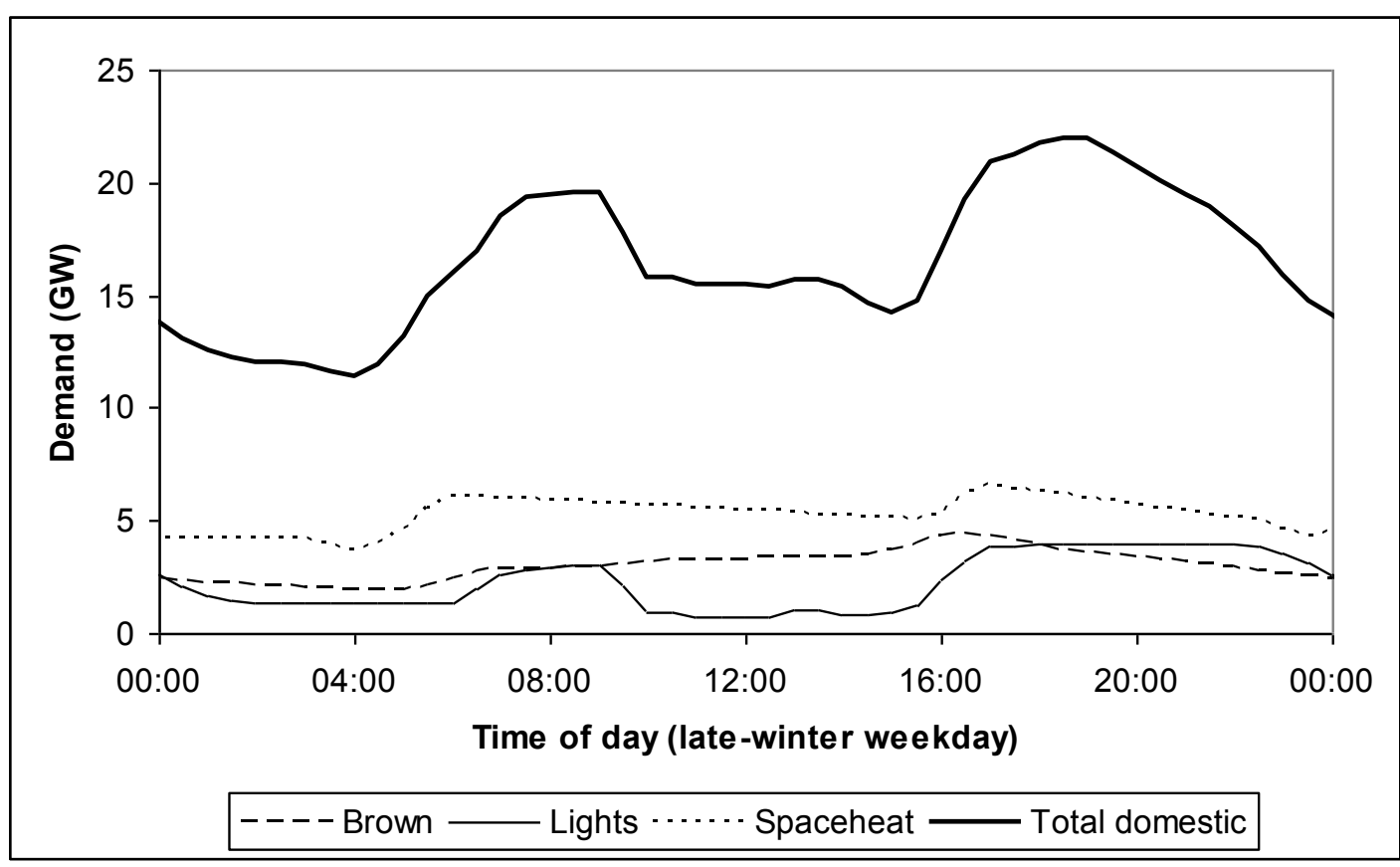

Fig. 1 Example of disaggregated UK domestic load profiles for a late winter weekday 
This paper is a postprint of a paper submitted to and accepted for publication in IET Renewable Power Generation (RPG) and is subject to IET copyright. The copy of record is available at [http://digitallibrary.theiet.org/]" and the paper is available through IEEE Xplore at [http://ieeexplore.ieee.org/xpls/abs_all.jsp?arnumber=5497937]

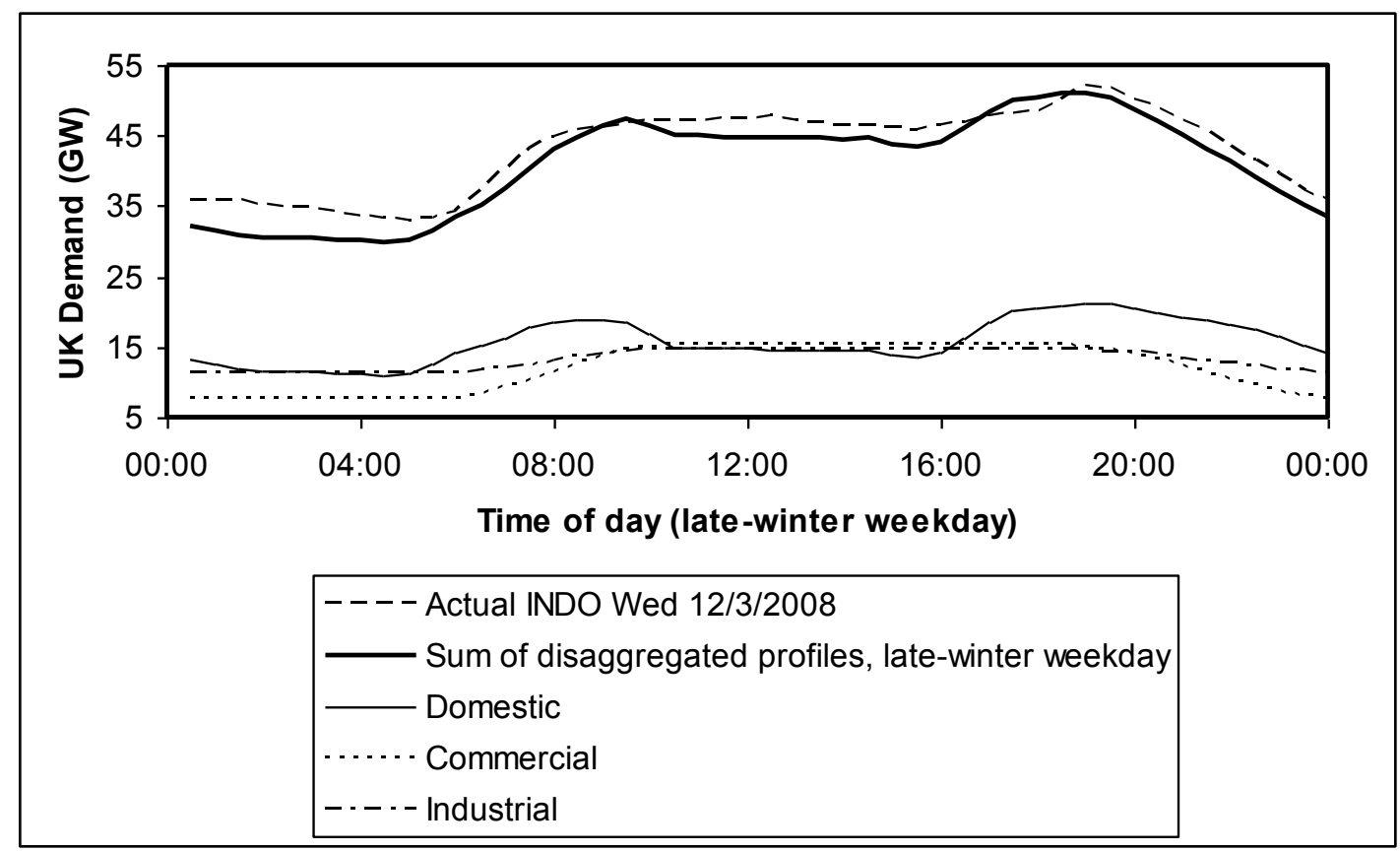

Fig. 2 Example of total UK load profiles for a late winter weekday

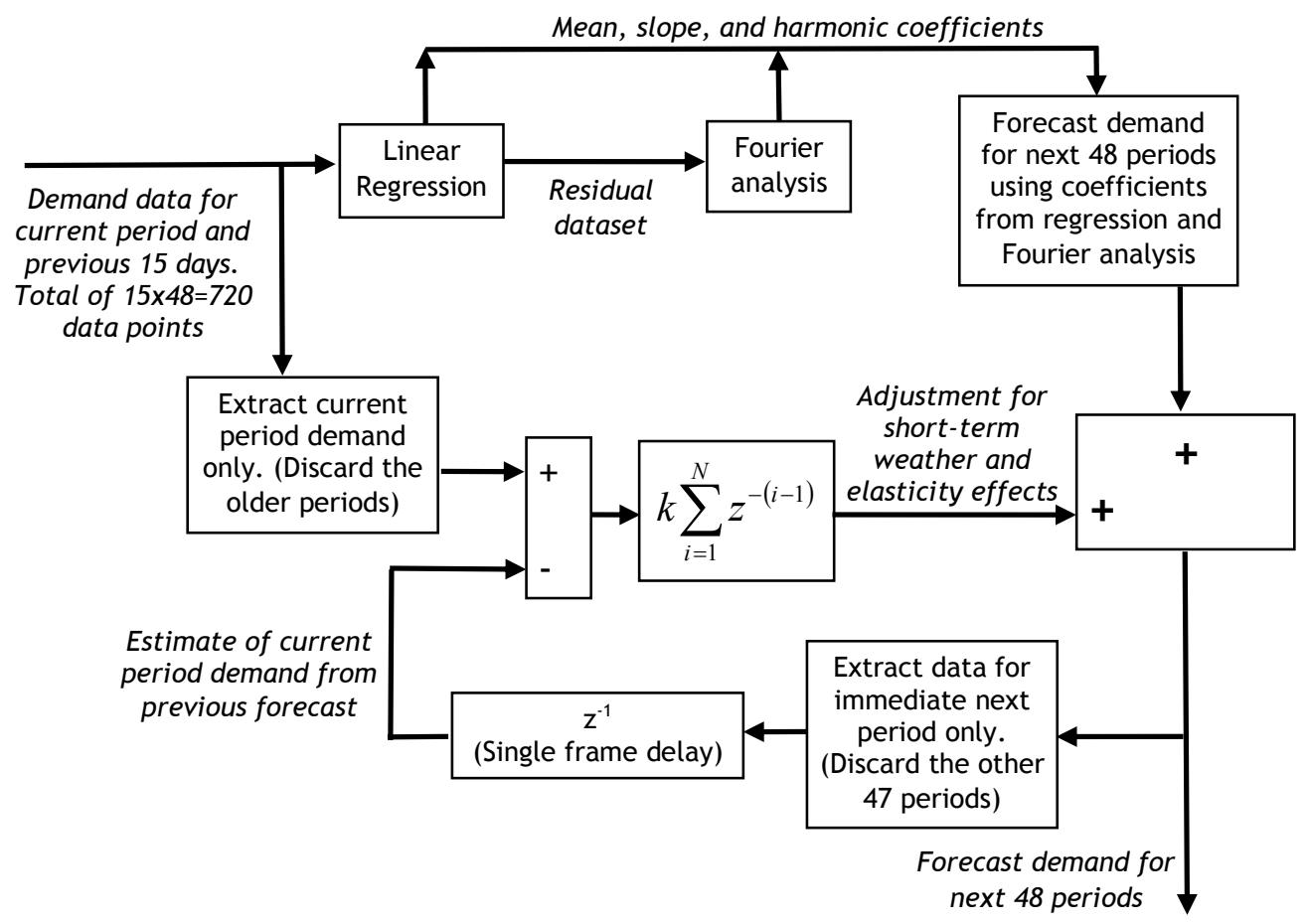

Fig. 3 Demand forecasting algorithm, executed every period 
This paper is a postprint of a paper submitted to and accepted for publication in IET Renewable Power Generation (RPG) and is subject to IET copyright. The copy of record is available at [http://digitallibrary.theiet.org/]" and the paper is available through IEEE Xplore at [http://ieeexplore.ieee.org/xpls/abs_all.jsp?arnumber=5497937]

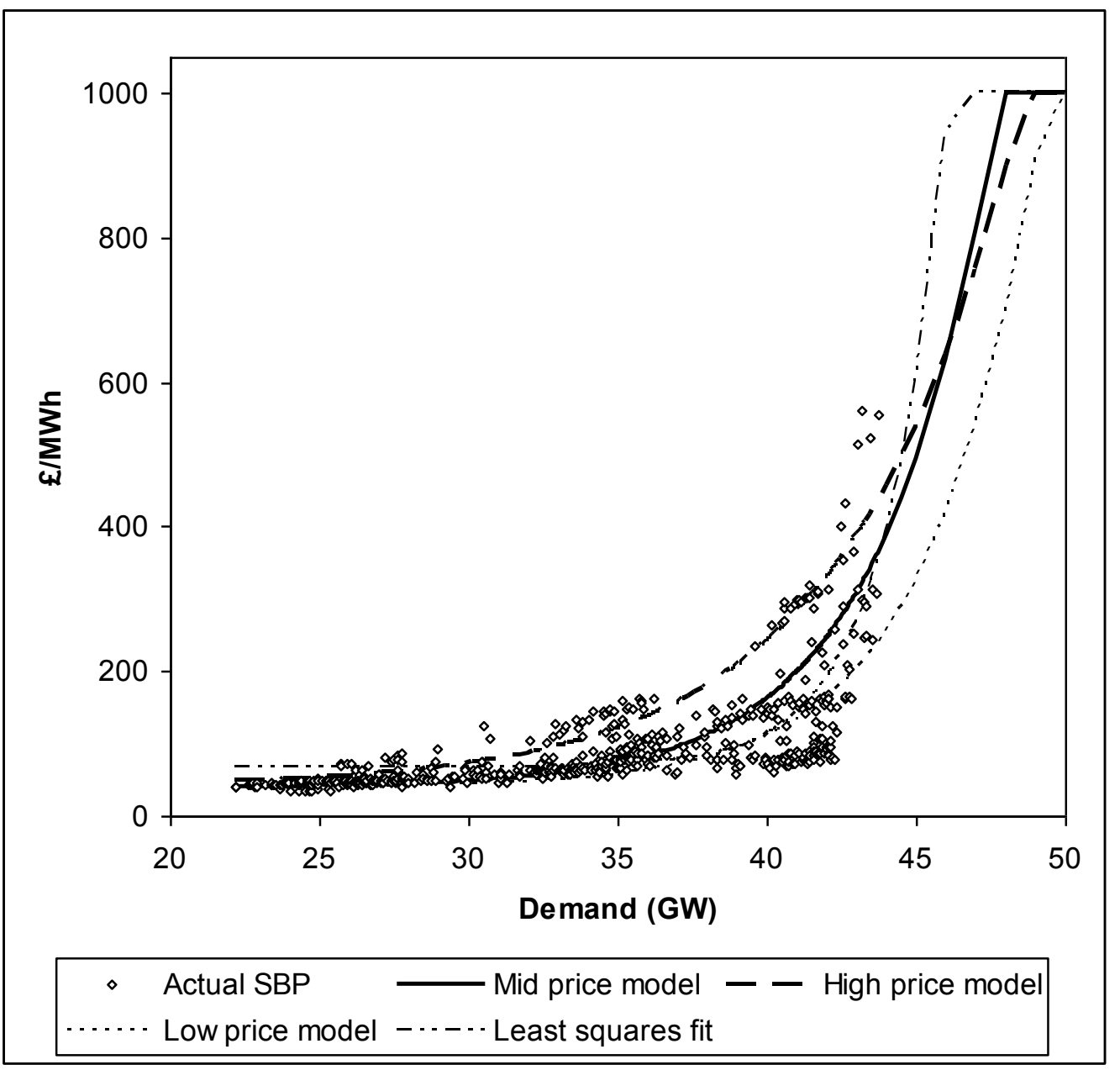

Fig. 4 Price model, based upon System Buy Price (SBP) data, capacity $\approx 45 G W$ 
This paper is a postprint of a paper submitted to and accepted for publication in IET Renewable Power Generation (RPG) and is subject to IET copyright. The copy of record is available at [http://digitallibrary.theiet.org/]" and the paper is available through IEEE Xplore at [http://ieeexplore.ieee.org/xpls/abs_all.jsp?arnumber=5497937]

\begin{tabular}{|c|c|c|}
\hline Load type & $\begin{array}{c}\text { Conservative } \\
\text { elasticity } \\
\text { (Case study 1) }\end{array}$ & $\begin{array}{c}\text { Optimistic } \\
\text { elasticity } \\
\text { (Case study 2) }\end{array}$ \\
\hline Brown & -0.5 & -1.0 \\
\hline Cooking & -0.1 & -0.2 \\
\hline Lights & -0.5 & -1.0 \\
\hline Wet & -0.1 & -0.2 \\
\hline Cold & 0 & 0 \\
\hline Water & -0.1 & -0.2 \\
\hline Spaceheat & -0.1 & -0.2 \\
\hline (Commercial) & 0 & -0.1 \\
\hline (Industrial) & 0 & -0.1 \\
\hline
\end{tabular}

Table 2 Potential elasticities of disaggregated load types

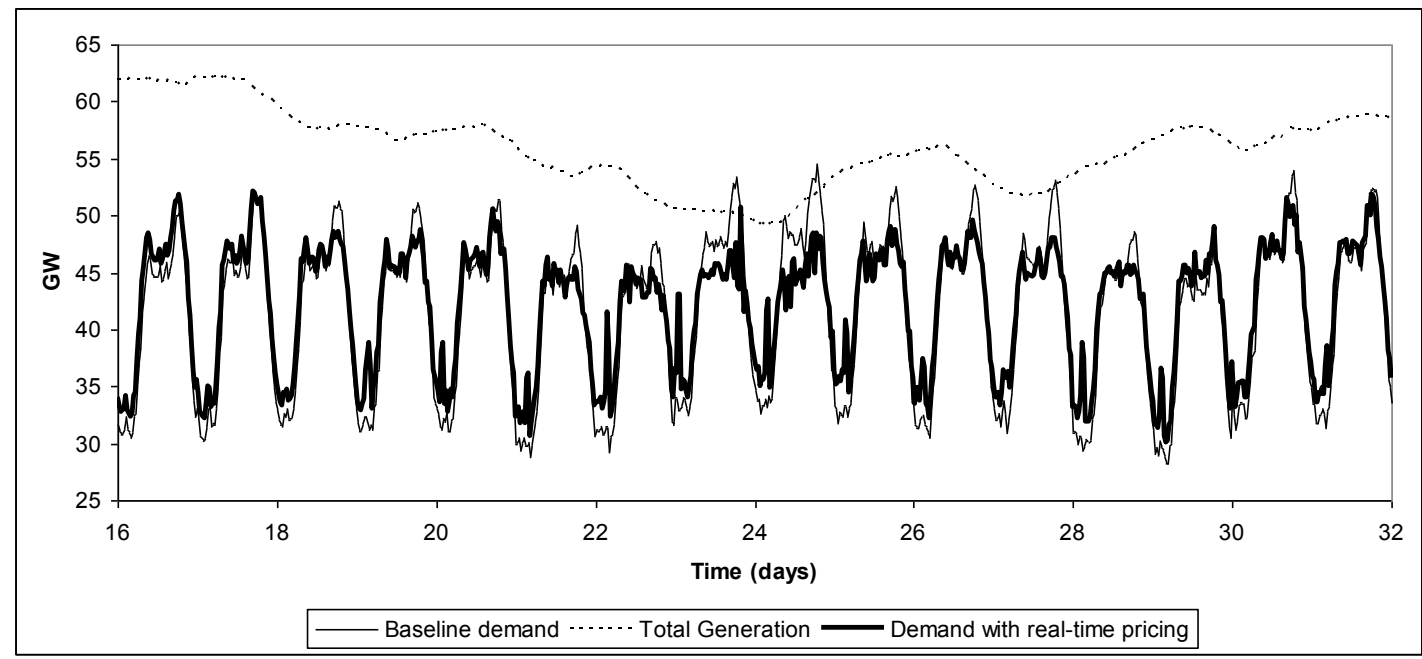

Fig. 5 Case study 1 overview; 16 days (Monday-Tuesday) shown

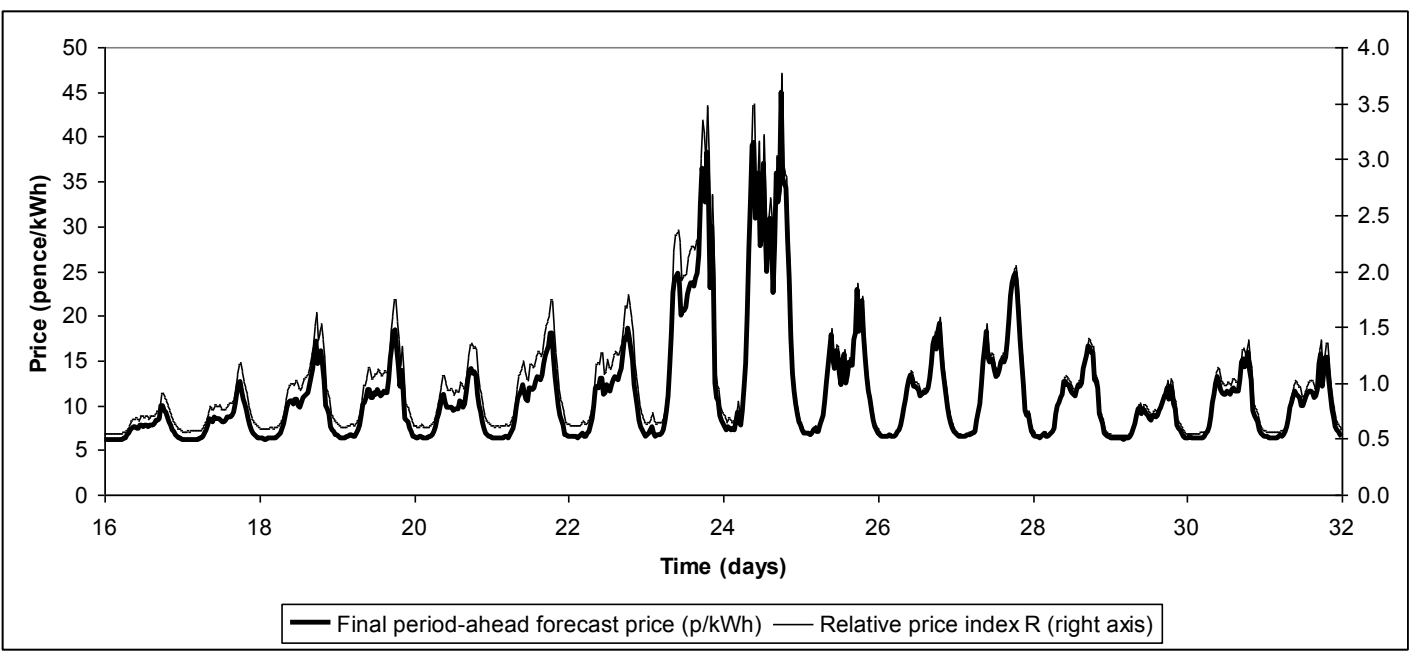

Fig. 6 Case study 1; pricing 
This paper is a postprint of a paper submitted to and accepted for publication in IET Renewable Power Generation (RPG) and is subject to IET copyright. The copy of record is available at [http://digitallibrary.theiet.org/]" and the paper is available through IEEE Xplore at [http://ieeexplore.ieee.org/xpls/abs_all.jsp?arnumber=5497937]

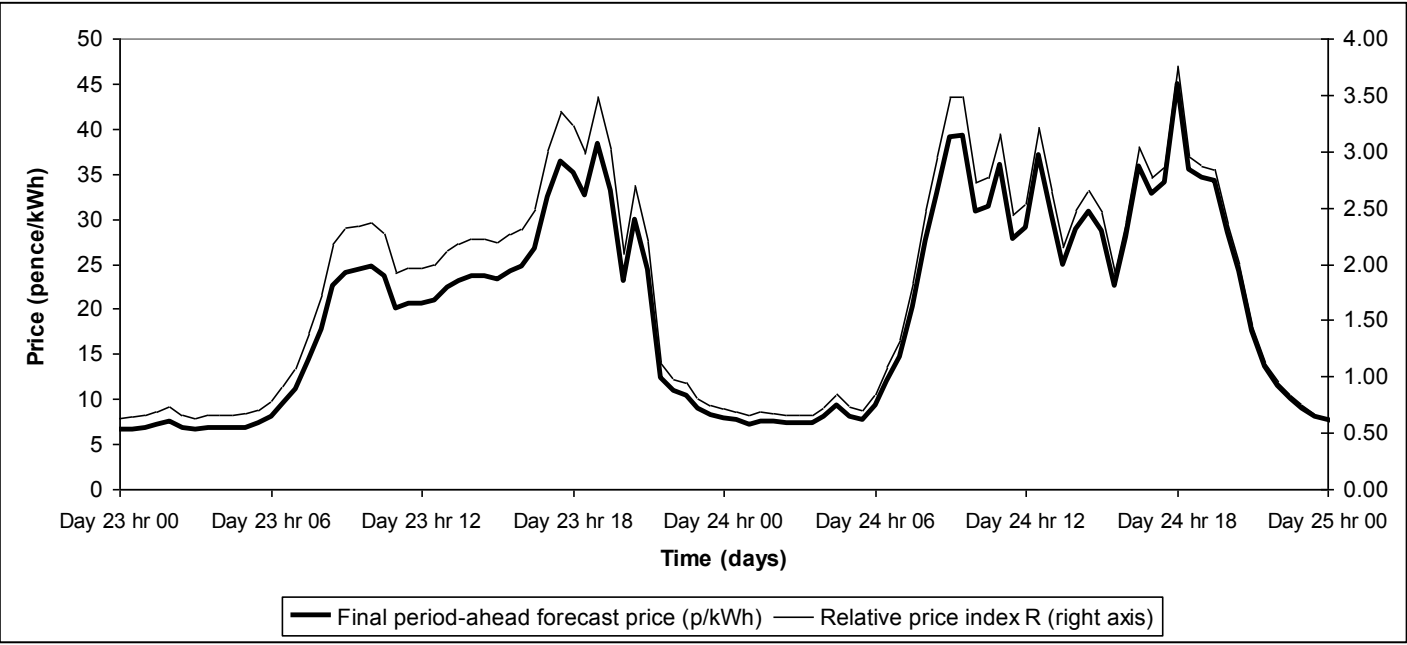

Fig. 7 Case study 1; pricing during days of high prices

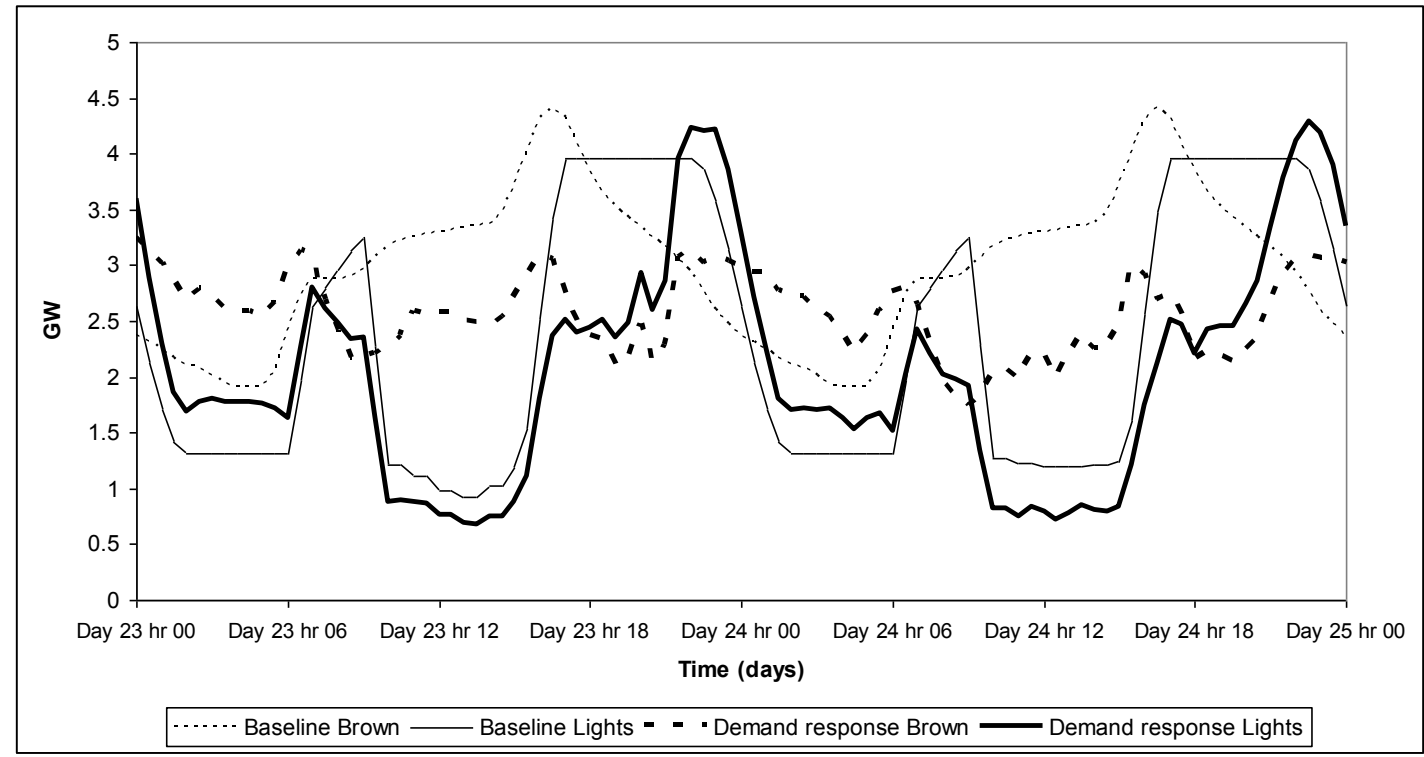

Fig. 8 Case study 1; elastic loads (brown and lighting) during days of high prices 
This paper is a postprint of a paper submitted to and accepted for publication in IET Renewable Power Generation (RPG) and is subject to IET copyright. The copy of record is available at [http://digitallibrary.theiet.org/]" and the paper is available through IEEE Xplore at [http://ieeexplore.ieee.org/xpls/abs_all.jsp?arnumber=5497937]

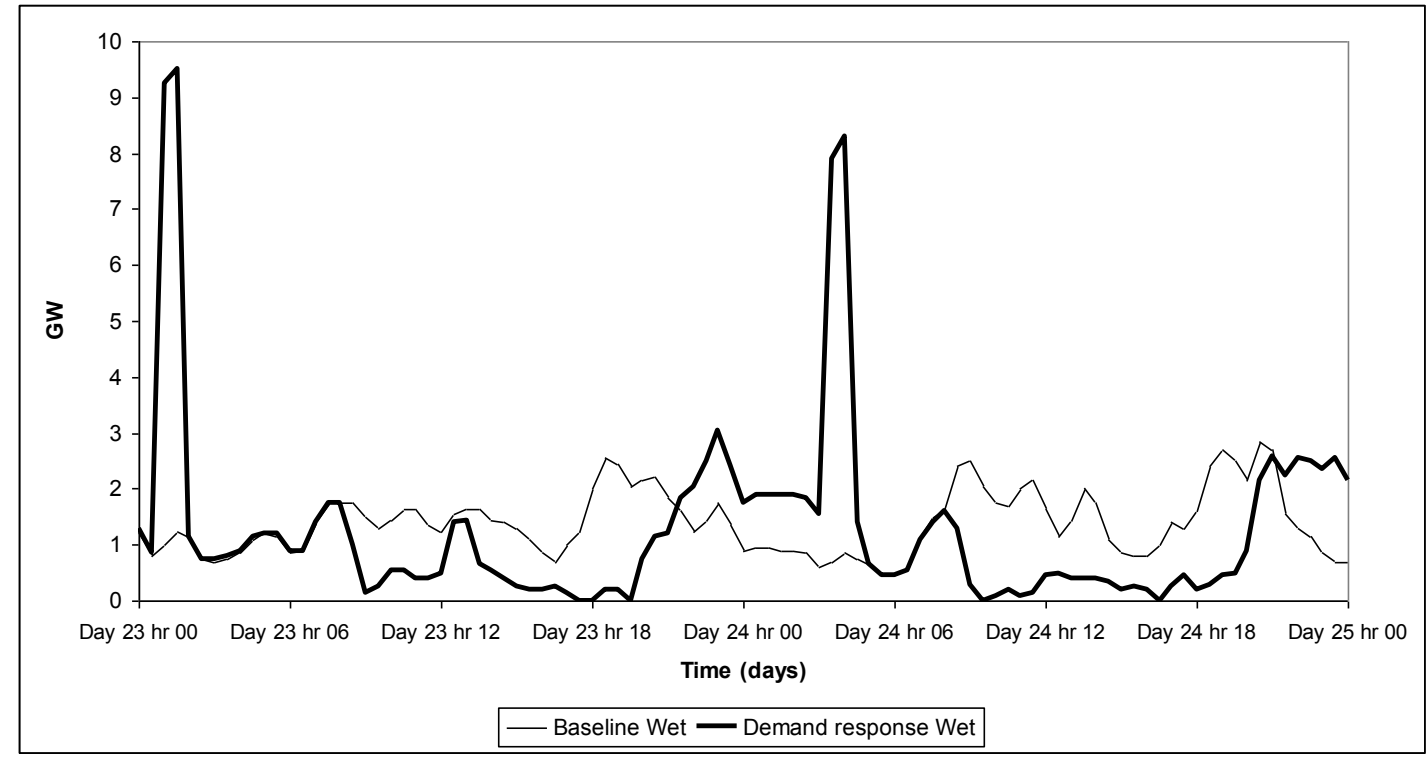

Fig. 9 Case study 1; load shifting of "wet" appliances

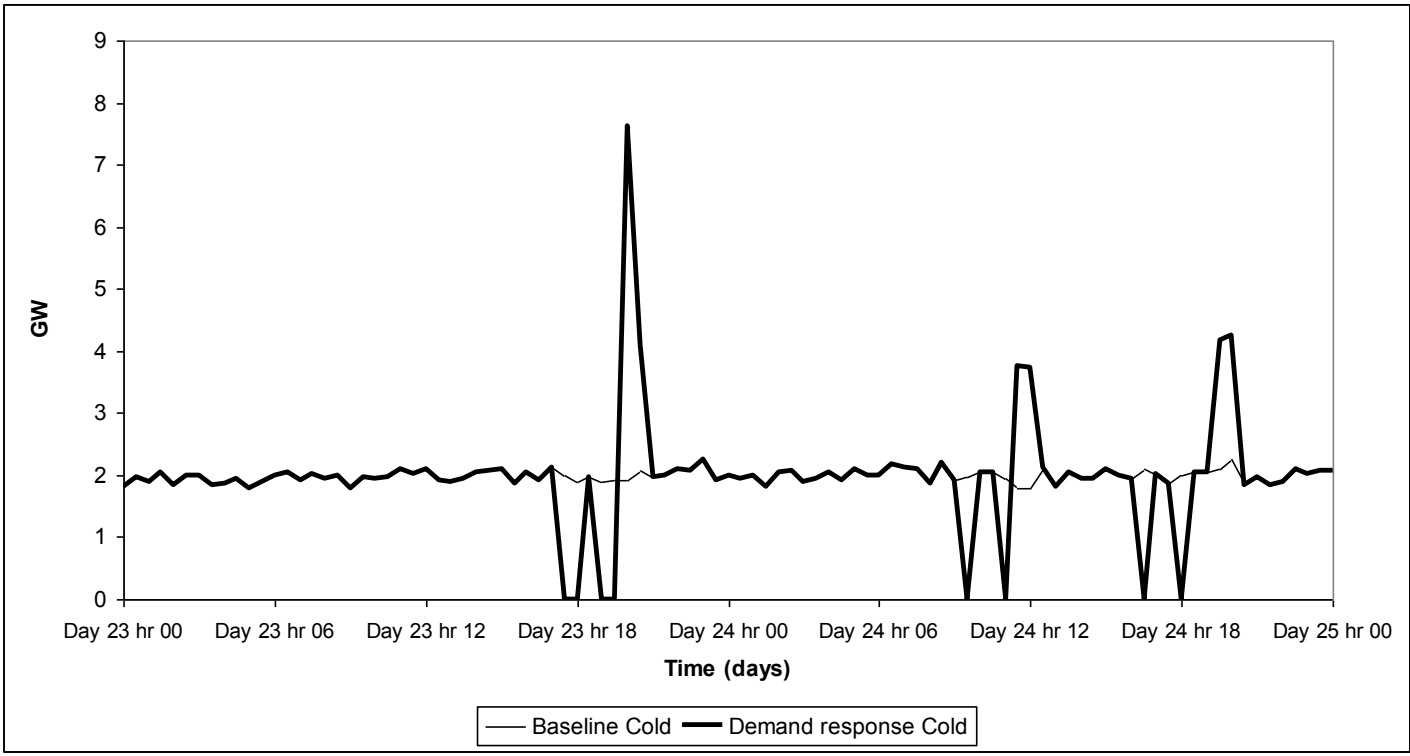

Fig. 10 Case study 1; load shifting of cold appliances due to critical peak pricing $(R>3)$ 
This paper is a postprint of a paper submitted to and accepted for publication in IET Renewable Power Generation (RPG) and is subject to IET copyright. The copy of record is available at [http://digitallibrary.theiet.org/]" and the paper is available through IEEE Xplore at [http://ieeexplore.ieee.org/xpls/abs_all.jsp?arnumber=5497937]

\begin{tabular}{|c|c|c|c|c|c|c|c|}
\hline & \multicolumn{2}{|c|}{$\begin{array}{c}\text { Demand average } \\
\mathrm{kWh} / \text { day }\end{array}$} & \multicolumn{2}{|c|}{$\begin{array}{l}\text { Cost (pence per kWh) } \\
\text { average to the } \\
\text { customer }\end{array}$} & \multicolumn{2}{|c|}{ Total annual bill } & \multirow{2}{*}{ Bill reduction } \\
\hline & Baseline & $\begin{array}{l}\text { Demand } \\
\text { Response }\end{array}$ & Baseline & $\begin{array}{l}\text { Demand } \\
\text { Response }\end{array}$ & Baseline & $\begin{array}{l}\text { Demand } \\
\text { Response }\end{array}$ & \\
\hline Total domestic & 12.80 & 13.75 & 12.50 & 9.60 & f584 & £481 & f103 \\
\hline $\begin{array}{l}\text { Houses using gas for } \\
\text { heating and cooking, } \\
\text { without wet shifting }\end{array}$ & 8.26 & 9.10 & 12.50 & 9.64 & £377 & £320 & 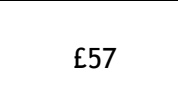 \\
\hline $\begin{array}{l}\text { Houses using gas for } \\
\text { heating and cooking, } \\
\text { with wet shifting }\end{array}$ & 8.35 & 9.19 & 12.50 & 9.26 & £381 & £311 & f70 \\
\hline $\begin{array}{l}\text { Houses using } \\
\text { electricity for } \\
\text { heating and cooking, } \\
\text { without wet shifting }\end{array}$ & 39.61 & 41.10 & 12.50 & 9.97 & $£ 1807$ & f1495 & £312 \\
\hline $\begin{array}{l}\text { Houses using } \\
\text { electricity for } \\
\text { heating and cooking, } \\
\text { with wet shifting }\end{array}$ & 39.42 & 40.87 & 12.50 & 9.85 & $£ 1799$ & f1469 & $£ 330$ \\
\hline
\end{tabular}

Table 3 Benefits of applying real-time prices to customers

\begin{tabular}{|c|c|c|}
\hline \hline & $\begin{array}{c}\text { Daily usage } \\
\text { increase } \\
\mathrm{kWh}\end{array}$ & Average annual bill reduction, per household \\
\hline Brown & 0.47 & $£ 15.76$ \\
\hline Lights & 0.34 & $£ 11.10$ \\
\hline Wet & 0.04 & $£ 18.11$ \\
\hline Cold & 0 & $£ 20.39$ \\
\hline
\end{tabular}

Table 4 Energy use changes (relative to Table 1) and bill reductions due to the application of real-time prices, for 4 appliance types

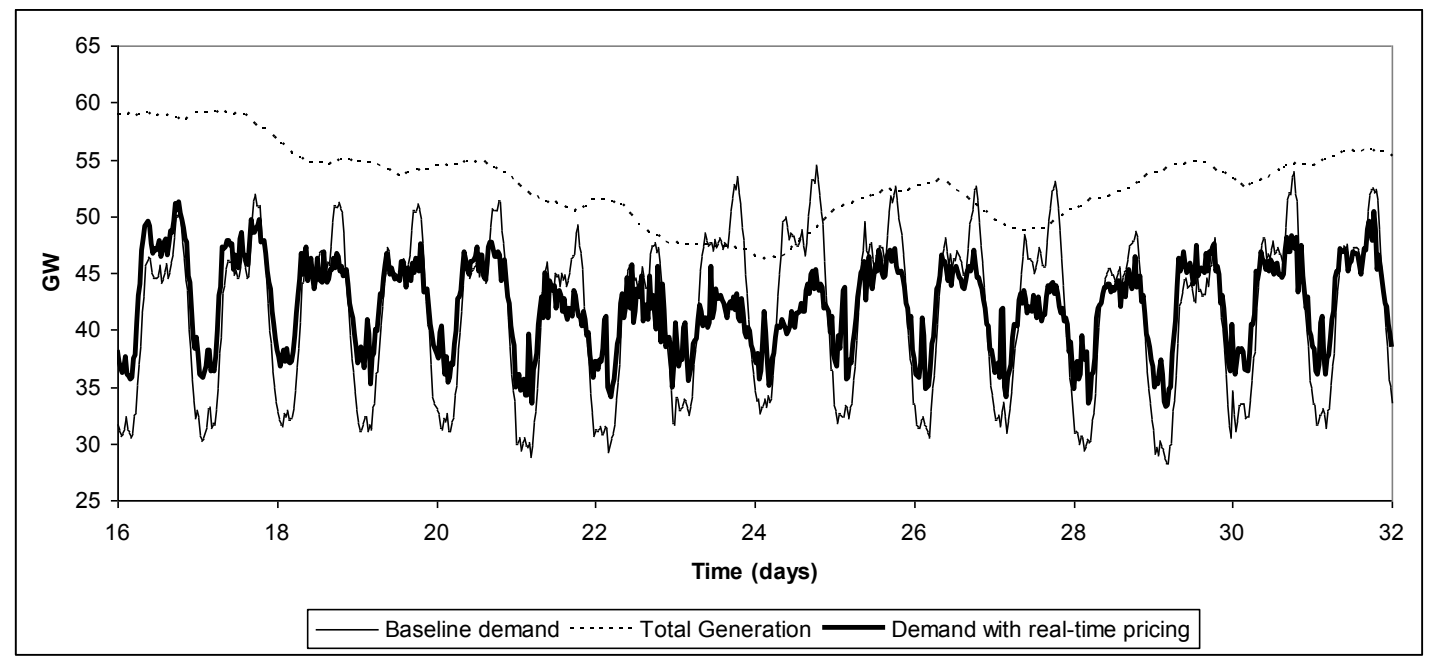

Fig. 11 Case study 2 overview; 16 days (Monday-Tuesday) shown 
This paper is a postprint of a paper submitted to and accepted for publication in IET Renewable Power Generation (RPG) and is subject to IET copyright. The copy of record is available at [http://digitallibrary.theiet.org/]" and the paper is available through IEEE Xplore at [http://ieeexplore.ieee.org/xpls/abs_all.jsp?arnumber=5497937]

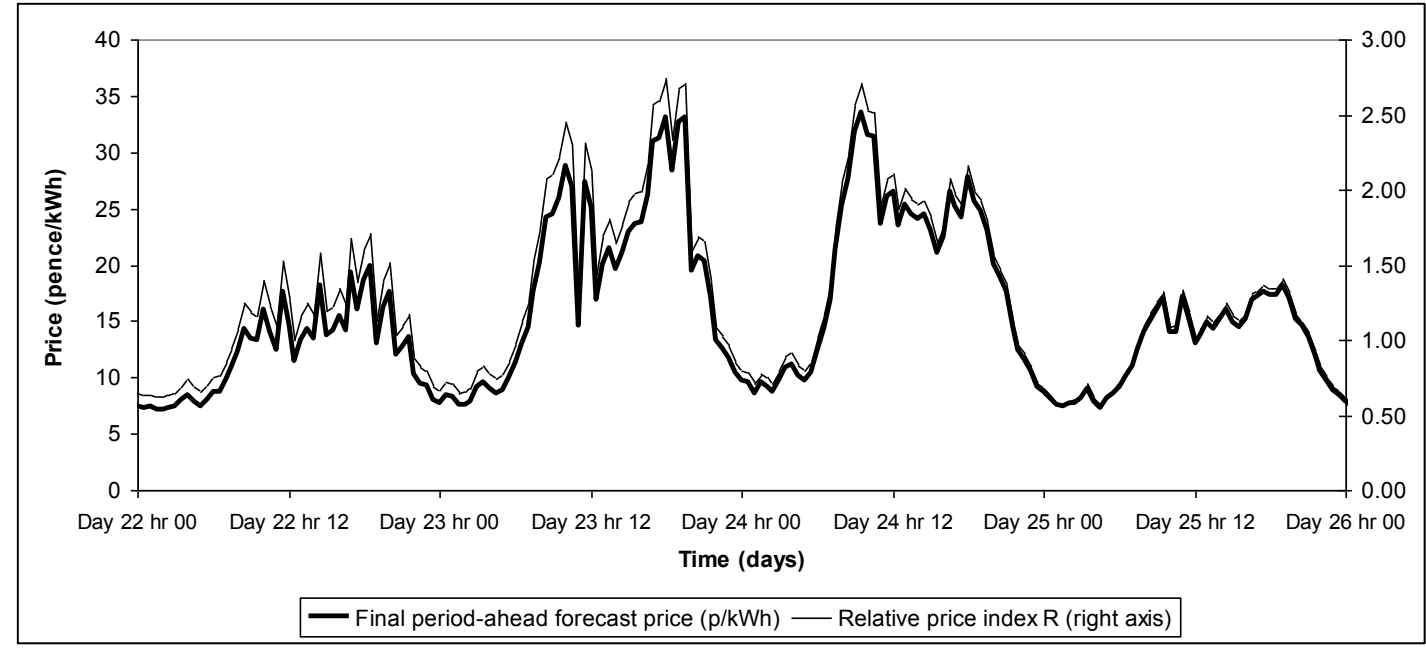

Fig. 12 Case study 2 pricing showing some short-term oscillations 